\title{
Science of eating time: A novel chronophysiological approach to optimize glucose-insulin dynamics and health
}

Akbar Nikkhah

Department of Animal Sciences, University of Zanjan, Zanjan, Iran; nikkhah@znu.ac.ir

Received 18 September 2011; revised 25 October 2011; accepted 12 November 2011

\begin{abstract}
Timing of eating is a life strategy that requires special considerations in healthy nutritional programs. Human body tolerates less glucose as evening begins, mainly because glucose is demanded most during more active times or daytime. A recommendation is being developed to avoid large night meals to help reduce risks of visceral adiposity, type-2 diabetes mellitus, hypertension, and cardiovascular issues. Optimal understanding of physiology in any given species requires optimal understanding of comparative animal-human physiology. Optimal animal physiology is understood with optimal perception of ruminant physiology with its unique complex systems biology. Thus, ruminants as irreplaceable human food producers are metabolically and economically suitable models to study cell, organ and whole body physiology. Evening vs. morning feeding of lactating cows increases eating rate, postprandial levels of rumen and peripheral metabolism, and milk and meat production. External cues and internal physiology may thus be synchronized to optimize production and health. Effective education will enable the public to be adequately cognizant of time of eating as a feasible strategy for the success of nutritional programs in optimizing health status.
\end{abstract}

Keywords: Eating Time; Glucose; Insulin; Health; Metabolism; Chronophysiology

\section{INTRODUCTION}

Conventionally, food types, composition, and quantity have been emphasized in affecting metabolism and health [1]. Timing of eating has not received deserving thoughts in modern nutritional programs. By definition, tissue nutrient supply may be synchronized with endo- genous physiological rhythms to optimize metabolism and health. Food intake patterns affect such physiological rhythms [2,3]. Suprachiasmatic nucleus (SCN) in the hypothalamus controls such rhythms [4]. Endogenous rhythms are mainly controlled by the SCN via photoperiod (Figure 1) [5]. Glucose, cortisol and insulin metabolism are regulated endogenously (Figures 1, 2). Exogenous rhythms are controlled mostly by external cues, such as feeding timing. Optimal understanding of physiology in any given species requires optimal understanding of comparative animal-human physiology. Optimal animal physiology is understood with optimal perception of ruminant physiology with its unique complex splanchnic and peripheral systems biology. Thus, ruminants as irreplaceable human food producers are metabolically and economically suitable theoretical and in several aspects applied models to study cell, organ and whole body physiology. Altering time of feeding alters postprandial rhythms of feed intake, rumen ecology, and

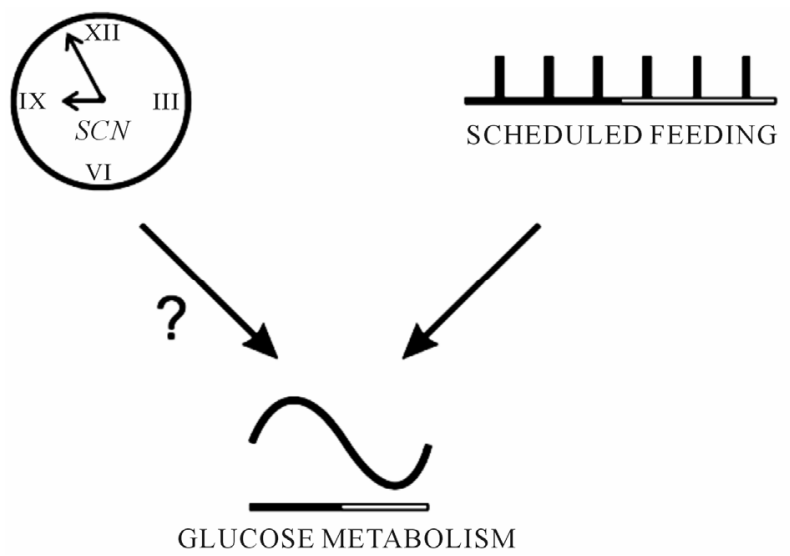

Figure 1. A life human model for direct and mediatory impacts of the hypothalamic suprachiasmatic nuclei (SCN; biological clock) on glucose metabolism in rats fed 6 meals a day with 4-h intervals. The SCN determines glucose metabolism and its blood concentration rhythms no matter whether or how feeding occurs. Black and white lines represent night (activity) and day (non-activity or resting) times, respectively [5]. 


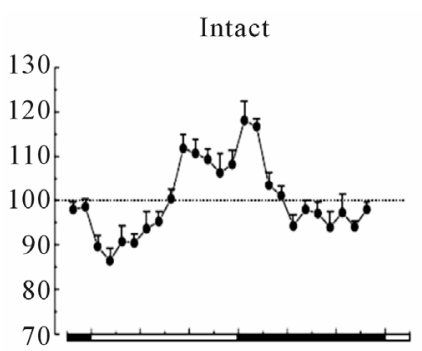

(a)

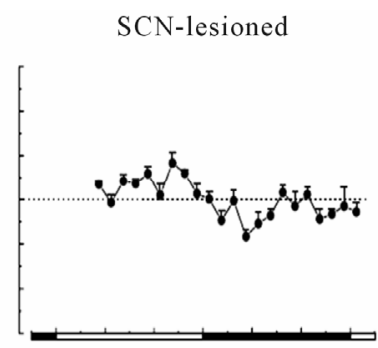

(b)
Figure 2. Basal peripheral blood glucose concentrations (as \% of the 24 h-mean \pm SEM) across the light-dark cycle in intact rats (left graph; $n=8$ ) and SCN-lesioned rats (right graph; $n=$ 7) with ad libitum feeding. The black line areas are night or rat's activity times [23].

peripheral metabolism in once-daily-fed dairy cows [2, 6-9]. Therefore, optimum nutrient metabolism and the risk of metabolic complexities (e.g., diabetes, obesity, liver diseases) would depend on when during the 24-h period nutrients are assimilated by splanchnic and peripheral tissues. The main objective is to emphasize time of eating as a feasible determinant of human health by integrating recent discoveries using human and animal models. A longer-term objective is to contribute to improving life quality of the highly-scheduled new century’s man.

\section{EVOLUTIONARY PHYSIOLOGY AND EATING TIME}

Evening instead of morning feeding can improve beef [10-12] and milk [2,9] production. Ruminants have evolved to ruminate mostly overnight when little grazing occurs and when the rumen has a greater volume than day-time [13] (Figure 3). Pasture is more nutritious in evening due to day-time photosynthesis in plant leaves [14]. Evening feeding, as such, increased postprandial eating rate, and improved peripheral nutrient supply in lactating cows [2,9]. Cows fed once daily at $2100 \mathrm{~h}$ exhibited a pre-feeding decline in blood glucose that progressed until 2-h post-feeding before reaching baseline at 4-h post-feeding [2,13]. Postprandial insulin surges were accordingly higher after evening vs. morning feeding [15]. Dairy cows eat when fresh feed is offered. Feed quantity ingested after feeding depends on time of day $[16,17]$. Anticipation of feed presentation time may elongate eating and increase intake in cows [18]. Increased eating rate after evening feeding suggests that cows may anticipate evening feeding more accurately than morning feeding [9,13]. The higher postprandial insulin and lower glucose in evening-fed cows may delay the glucagon-driven satiety and, thereby, contribute to increased eating rate. Evolutionarily, rumination occurs mostly overnight (Figure 3 ). The greater nocturnal vs.

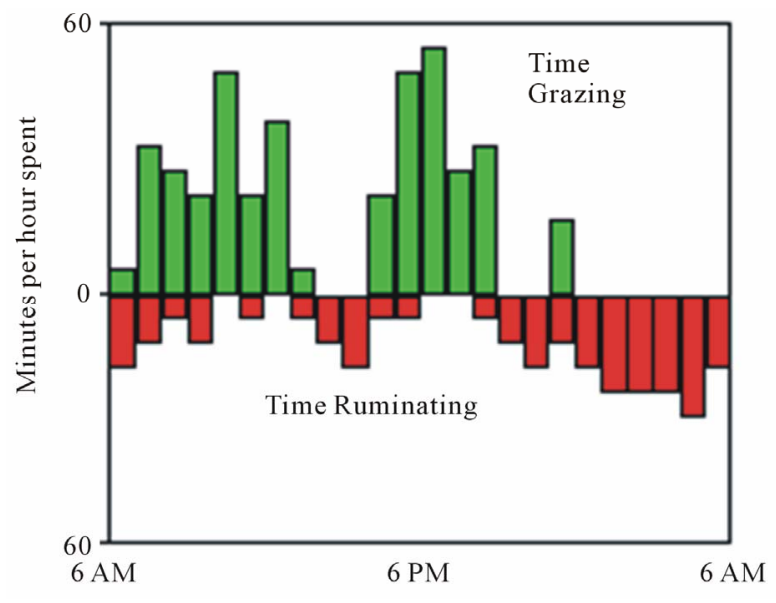

Figure 3. Diurnal patterns of rumination and eating in steers grazing alfalfa pastures [27].

diurnal rumen volume and fermentation capacity in grazing [19] and intensively-housed [13] lactating cows are thus consistent. Altogether, ruminant model studies support the important mediatory impacts of feeding/eating timing on circadian rhythms of eating and nutrient metabolism.

\section{HUMAN CIRCADIAN PHYSIOLOGY AND EATING TIME}

Blood glucose and insulin have endogenous rhythms $[5,20]$. This means that insulin sensitivity and glucose tolerance have 24-h rhythmicity, apart from how and which food is consumed [5,21]. Human glucose tolerance declines as day progresses and night begins [22]. Thus, humans cannot metabolize glucose effectively in evening, since glucose is demanded most during active day-time (Figure 2). Increased day-time glucose tolerance is due to increased pancreatic $\beta$-cells insulin secretion, increased glucose transporters, and increased insulin receptors availability and sensitivity. Impaired insulin sensitivity is a result of reduced access and sensitivity of insulin receptors, which reduces peripheral glucose uptake $[5,20]$. In addition, human glucose tolerance depends on time of the 24-h period regardless of sleep, and on sleep regardless of time of the 24-h period [21]. Therefore, both the circadian SCN clock and photoperiod regulate blood glucose rhythmicity [21,22] (Figures 1, 2). The SCN and eating time separately regulate glucose metabolism and intake patterns [23]. These evolutionary facts are being integrated into a recommendation to avoid large evening meals to reduce risks of visceral adiposity, type-2 diabetes mellitus, and cardiovascular disorders. Shift-workers are prone to increased overnight food intake that is not effectively assimilated and tolerated by the cells. Also, the SCN- and eating time-driven rhythms of nutrients and hormones are perturbed. Thus, 
shift-workers need to be under special diurnal and nocturnal nutritional programs to enable coping with the altered environmental chronophysiological properties and to minimize metabolic complications.

\section{ENDOCRINOLOGY OF GLUCOSE RHYTHMS}

Glucose concentrations rise at the end of "resting period", which is "dark period" in human [23]. The glucose rise just before the onset of the activity period is known as "dawn-phenomenon" [22]. The blood glucose peak coincides with circadian rises in corticosterone levels. The glucocorticoid peak contributes to the elevated glucose output and insulin requirement [23]. Moreover, the nocturnal surges in growth hormone (GH) are of importance [24]. Increased GH-driven hepatic glucose production is thus a main cause of the early morning glucose rise [25]. Moreover, melatonin is involved in glucose rhythms regulation. Melatonin secretion is induced by darkness and increases postprandial insulin requirements [20]. Reduced nocturnal glucose tolerance may be, at least partly, mediated by increased melatonin secretion [21]. Reduced glucose tolerance reflects reductions in glucose demands [21,22], which is meaningful as glucose is demanded least during inactive night-time. Accordingly, reduced glucose tolerance could be an evolutionary preparation for the resting body to cope with the darkness [26]. Avoiding large night meals would allow melatonin to better optimize nocturnal metabolism.

\section{CONCLUSION}

Timing of eating has received highly inadequate considerations in public education. Glucose tolerance decreases as evening begins, suggesting avoiding large evening meals to reduce risks of visceral adiposity, diabetes mellitus, hypertension, and related cardiovascular abnormalities. Shift-workers with perturbed SCN- and eating time-driven rhythms of nutrients and hormones require special diurnal and nocturnal nutritional regimes. In ruminant models, evening vs. morning feeding increases postprandial eating rate, and rumen and peripheral metabolites availability, thus improving milk and meat production. Integrating these discoveries lead to an implication to synchronize external cues with internal animal-human physiology to maximize nutrient efficiency and optimize health. Persistent education and data dissemination will lead the incorporation of eating time into successful nutritional programs.

\section{ACKNOWLEDGEMENTS}

The Ministry of Science, Research and Technology, and University of Zanjan (Iran) are gratefully acknowledged for supporting the au- thor's programs of optimizing global science education.

\section{REFERENCES}

[1] Dietary Reference Intakes (DRI) (2007) Recommended Intakes for Individuals, Food and Nutrition Board, Institute of Medicine, National Academies. National Academy of Sciences, Washington DC.

[2] Nikkhah, A., Furedi, C.J., Kennedy, A.D., Crow, G.H. and Plaizier, J.C. (2008) Effects of feed delivery time on feed intake, rumen fermentation, blood metabolites and productivity of lactating cows. Journal of Dairy Science, 91, 1-12.

[3] Piccione, G. and Caola, G. (2002) Review: Biological rhythm in livestock. Journal of Veterinary Science, 3, 145-157.

[4] Sehgal, A. (2004) Molecular biology of circadian rhythms. John Wiley \& Sons, Inc., Hoboken. doi:10.1002/0471459186

[5] la Fleur, S.E., Kalsbeek, A., Wortel, J., Fekkes, M.I. and Buijs, R.M. (2001) A daily rhythm in glucose tolerance: A role for the suprachiasmatic nucleus. Diabetes, 50, 12371243. doi:10.2337/diabetes.50.6.1237

[6] Nikkhah, A. (2011) Bioscience of ruminant intake evolution: Feeding time models. Advances in Bioscience and Biotechnology, 2, 271-274. doi:10.4236/abb.2011.24039

[7] Nikkhah, A. (2011) Ruminant chronophysiological management: An emerging bioscience. Open Access Animal Physiology, 3, 9-12. doi:10.2147/OAAP.S24071

[8] Nikkhah, A. (2011) Postprandial rhythms of circulating urea in lactating dairy cows: Feeding timing and diet effects. Biological Rhythm Research, Article in Press. doi:10.1080/09291016.2011.614792

[9] Nikkhah, A., Furedi, C.J., Kennedy, A.D., Scott, S., Crow, G.H. and Plaizier, J.C. (2011) Feed delivery at 2100 h vs. $0900 \mathrm{~h}$ for lactating dairy cows. Canadian Journal of Animal Sciences, 91, 113-122. doi:10.4141/CJAS10012

[10] Kennedy, A.D., Bergen, R.D., Lawson, T.J., Small, J.A. and Veira, D.M. (2004) Effects of evening feeding and extended photoperiod on growth, feed efficiency, live animal carcass traits and plasma prolactin of beef heifers housed outdoors during two Manitoba winters. Canadian Journal of Animal Sciences, 84, 491-500. doi:10.4141/A03-028

[11] Schwartzkopf-Genswein, K.S., Beauchemin, K.A., McAllister, T.A., Gibb, D.J., Streeter, M. and Kennedy, A.D. (2004) Effect of feed delivery fluctuations and feeding time on ruminal acidosis, growth performance, and feeding behavior of feedlot cattle. Journal of Animal Science, 82, 3357-3365.

[12] Small, J.A., Kennedy, A.D., Veira, D.M., McCaughey, W.P. and Ward, D.R. (2004) Time of feeding and growth promotant effects on the winter growth performance and carcass traits of steers. Canadian Journal of Animal Sciences, 84, 133-144. doi:10.4141/A03-048

[13] Nikkhah, A., Plaizier, J.C. and Kennedy, A.D. (2011) 
Rumen volume and passage kinetics depend on feeding time (0090 h vs. 2100 h). Journal of Dairy Science, 94, 374-375.

[14] Fisher, D.S., Mayland, H.F. and Burns, J.C. (2002) Variation in ruminant preference for alfalfa hays cut at sunup and sundown. Crop Science, 42, 231-237. doi:10.2135/cropsci2002.0231

[15] Furedi, C., Kennedy, A.D., Nikkhah, A. and Plaizier, J.C. (2006) Glucose tolerance and diurnal variation of circulating insulin in evening and morning fed lactating cows. Advances in Dairy Technology, 18, 356.

[16] DeVries, T.J., von Keyserlingk, M.A.G. and Beauchemin, K.A. (2003) Short communication: Diurnal feeding pattern of lactating dairy cows. Journal of Dairy Science, 86, 4079-4082. doi:10.3168/jds.S0022-0302(03)74020-X

[17] Haley, D.B., Rushen, J. and de Passille, A.M. (2000) Behavioral indicators of cow comfort: Activity and resting behaviour of dairy cows housed in two types of housing. Canadian Journal of Animal Sciences, 80, 257-263. doi:10.4141/A99-084

[18] Phillips, C.J. and Rind, M.I. (2001) The Effects of frequency of feeding a total mixed ration on the production and behavior of dairy cows. Journal of Dairy Science, 84, 1979-1987. doi:10.3168/jds.S0022-0302(01)74641-3

[19] Taweel, H.Z., Tas, B.M., Dijkstra, J. and Tamminga, S. (2004) Intake regulation and grazing behavior of dairy cows under continuous stocking. Journal of Dairy Science, 87, 3417-3427. doi:10.3168/jds.S0022-0302(04)73477-3

[20] La Fleur, S.E., Kalsbeek, A., Wortel, J., van der Vliet, J. and Buijs, R.M. (2001) Role for the pineal and melatonin in glucose homeostasis: Pinealectomy increases night- time glucose concentrations. Journal of Neuroendocrinology, 13, 1025-1032. doi:10.1046/j.1365-2826.2001.00717.x

[21] Van Cauter, E., Biackman, J., Roland, D., Spire, J-P., Refetoff, S. and Polonsky, K.S. (1991) Modulation of glucose regulation and insulin secretion by circadian rhythmicity and sleep. Journal of Clinical Investigations, 88, 934-942. doi:10.1172/JCI115396

[22] Arslanian, S., Ohki, Y., Becker, D.J. and Drash, A.L. (1990). Demonstration of a dawn phenomenon in normal adolescents. Hormone Research, 34, 27-32. doi:10.1159/000181791

[23] La Fleur, S.E. (2003) Daily rhythms in glucose metabolism: Suprachiasmatic nucleus output to peripheral tissue. Journal of Neuroendocrinology, 15, 315-322. doi:10.1046/j.1365-2826.2003.01019.x

[24] Kalsbeek, A., Fliers, E., Romijn, J., la Fleur, S., Wortel, J., Bakker, O., Endert, E. and Buijs, R. (2001) The suprachiasmatic nucleus directly generates the diurnal changes in plasma leptin levels. Endocrinology, 142, 2677-2685. doi:10.1210/en.142.6.2677

[25] Boden, G., Chen, X. and Urbain, J.L. (1996) Evidence for a circadian rhythm of insulin sensitivity in patients with NIDDM caused by cyclic changes in hepatic glucose production. Diabetes, 45, 1044-1050. doi:10.2337/diabetes.45.8.1044

[26] Lima, F.B., Machado, U.F., Bartol, I., et al. (1998) Pinealectomy causes glucose intolerance and decreases adipose cell responsiveness to insulin in rats. American Journal of Physiology, 275, E934-E941.

[27] Phillips, C. (2002) Cattle behaviour and welfare. Blackwell Science Ltd. Oxford, UK, 264. 